\title{
Nanoscale
}

Check for updates

Cite this: Nanoscale, 2021, 13, 6234

\section{Perovskite and quantum dot tandem solar cells with interlayer modification for improved optical semitransparency and stability $\uparrow$}

\author{
Aneta Andruszkiewicz, ${ }^{a}$ Xiaoliang Zhang, (D) ${ }^{\mathrm{b}}$ Malin B. Johansson, ${ }^{a}$ Lin Yuan ${ }^{\mathrm{a}}$ and \\ Erik M. J. Johansson (iD *a
}

\begin{abstract}
In this work, four-terminal (4T) tandem solar cells were fabricated by using a methylammonium lead iodide $\left(\mathrm{MAPb}_{3}\right)$ perovskite solar cell (PSC) as the front-cell and a lead sulfide (PbS) colloidal quantum dot solar cell (CQDSC) as the back-cell. Different modifications of the tandem interlayer, at the interface between the sub-cells, were tested in order to improve the infrared transparency of the perovskite subcell and consequently increase the utilization of infrared (IR) light by the tandem system. This included the incorporation of a semi-transparent thin gold electrode $(\mathrm{Au})$ on the $\mathrm{MAPb}_{3}$ solar cell, followed by adding a molybdenum(VI) oxide $\left(\mathrm{MoO}_{3}\right)$ layer or a surlyn layer. These interlayer modifications resulted in an increase of the IR transmittance to the back cell and improved the optical stability, compared to that in the reference devices. This investigation shows the importance of the interlayer, connecting the PSC with a strong absorption in the visible region and the CQDSC with a strong infrared absorption to obtain efficient next-generation tandem photovoltaics (PVs).
\end{abstract}

Received 24th November 2020 Accepted 12th February 2021 DOI: $10.1039 /$ d0nr08375e rsc.li/nanoscale semiconductors - materials with very expensive manufacturing processes. ${ }^{4}$ Therefore, developing efficient tandem devices using low-cost materials and methods remains an important challenge.

In the last decade, tandem device structures using numerous arrangements of photoactive materials for complementary absorption have been studied. Among them, metal halide perovskite solar cells have shown tremendous potential to become a low-cost alternative for front-cells in tandem solar cells, and also for conventional photovoltaics. Metal halide perovskite solar cells in the last decade have achieved the most rapid efficiency growth of any photovoltaic material, showing a PCE increase from $3.8 \%{ }^{5}$ up to the current record value of $25.2 \%{ }^{6}$ This remarkable performance of perovskite solar cells is possible due to their optoelectronic properties, including broad light absorption spectrum, low exciton binding energies and effective masses, long lifetime and high mobility. ${ }^{7-10}$ Other advantages of perovskite PVs are low cost and low-temperature fabrication in comparison with the traditional silicon solar cells. Moreover, the bandgap of metal halide perovskites with the formula $\mathrm{ABX}_{3}(\mathrm{~A}$ - monovalent cation, $\mathrm{B}$ - divalent cation, and $\mathrm{X}$ - halide anion) can be easily adjusted from 1.2 to $2.3 \mathrm{eV}$, which makes them ideal candidates for wide-bandgap absorbers in multi-junction PVs. Currently one of the best perovskite tandem photovoltaic devices can only absorb photons with a wavelength shorter than $\sim 1000 \mathrm{~nm}$ (bandgap of $\gtrsim 1.24 \mathrm{eV}$ ). ${ }^{11,12}$ Moreover, the absorption range of the leading perovskite/Si 
tandem solar cells is limited to approximately $1100 \mathrm{~nm}$ (bandgap of $\gtrsim 1.12 \mathrm{eV}$ ). ${ }^{13}$ It is crucial to indicate that these devices still cannot effectively harvest and convert the infrared part of the solar spectrum.

Colloidal quantum dots (CQDs) are a material of great potential in optoelectronic applications such as photovoltaics. ${ }^{14-16}$ They offer tunable band gaps $(0.5-2.0 \mathrm{eV})$, strong infrared absorption and low-cost solution processability. Given these advantages, they quickly took a firm position in the PV materials community. Lead sulfide colloidal quantum dots solar cells (PbS CQDSCs) stand out among the CQD solutionprocessed photovoltaics. Since they were first synthesized their efficiency has increased more than ten times, reaching over $13 \%{ }^{16}$ This was possible due to the significant progress in surface modification and incorporation of solution-phase ligand-exchange techniques ${ }^{17}$ in the fabrication process. Due to the CQDs' ability to reach significantly lower bandgap energy values, way beyond those of silicon and perovskites, ${ }^{18}$ they can serve as harvesters of infrared light transmitted through wide-bandgap front-cells in multi-junction tandem photovoltaics. ${ }^{19}$ Recent theoretical calculations by Karani et al. demonstrated tremendous potential for the tandem devices comprised of CQD bottom sub-cell and perovskite top cell, achieving a theoretical efficiency of $40 \%{ }^{20}$ To date attempts to fabricate perovskite-CQD tandem devices have reported PCEs of $11 \%$ for 2 -terminal $(2 \mathrm{~T})$ and $20.2 \%$ for 4 -terminal (4T) tandem configurations. ${ }^{21,22}$

Among the available tandem structures, $4 \mathrm{~T}$ tandem devices seem to be more attractive due to no current-matching limitation and therefore enabling easier manufacturing processes. $^{23}$ However, constructing a successful $4 \mathrm{~T}$ tandem solar cell entails many challenges. These involve the fabrication of an efficient, highly transparent and stable perovskite front sub-cell, the development of a spectrally matched CQD back cell with strong IR absorption and the design and modification of a semi-transparent interlayer between them. This interlayer is of crucial importance here, since it can provide semi-transparency and optical stability to the perovskite sub-cell. ${ }^{22-24}$

\section{Results and discussion}

In this work, a methylammonium lead iodide $\left(\mathrm{MAPbI}_{3}\right)$ perovskite solar cell was incorporated as the front sub-cell and a lead sulfide colloidal quantum dot solar cell was employed as the back sub-cell, as shown in Fig. 1a. Such a material combination gives spectrally matched efficient and broad absorption of both visible and near infrared light (Fig. 1b). ${ }^{20}$ The perovskite absorbs to almost $800 \mathrm{~nm}$, and the CQDs to around $1100 \mathrm{~nm}$ (see Fig. S1†). To improve the transmission of lowerenergy photons through the cell, so that the absorption of those photons by the CQDSC can be enhanced, the interlayer is modified in this work. This includes the incorporation of a semi-transparent thin gold electrode (Au) on top of the $\mathrm{MAPbI}_{3}$ solar cell, followed by the addition of a molybdenum (vi) oxide $\left(\mathrm{MoO}_{3}\right)$ or an ionomer resin interlayer. Both the thin metal electrode and metal oxide were already incorporated in our previous work to improve the transmittance of solar cell devices. $^{25,26}$ The ionomer resin used in this work was 'Surlyn' with the structure of an ethylene and methacrylic acid copolymer complexed with metal ions. It comes in the form of milky clear sheets whose transparency increases as the thickness decreases. Surlyn has high transparency, high chemical resistance, flexibility, low sealing temperature and excellent chemical compatibility with other components of solar cells. The socalled 'surlyn encapsulation' eliminates the air 'layer' between the sub-cells and consequently lowers the reflections inside the system, for improved light coupling between them. Simultaneously it improves the stability of the perovskite subcell. In this work, surlyn with a thickness of $25 \mu \mathrm{m}$ was used.

Usually the perovskite solar cell is fabricated with an $80 \mathrm{~nm}$ thick gold top electrode. However, this counter electrode thick-
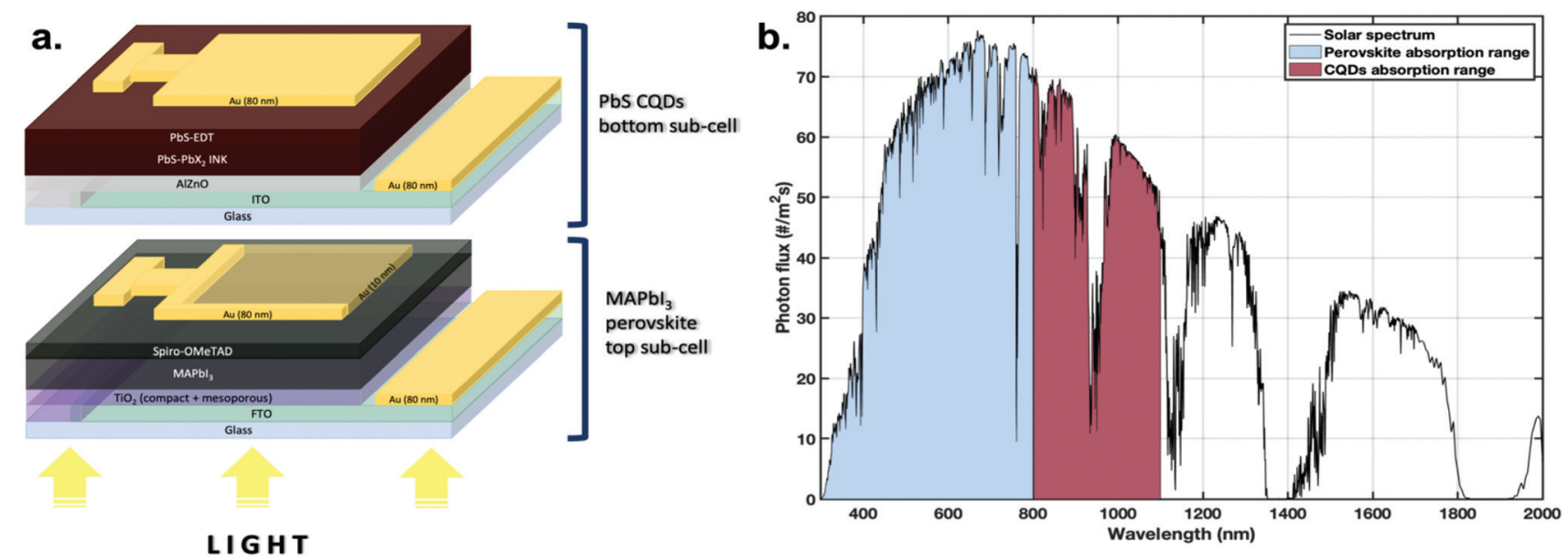

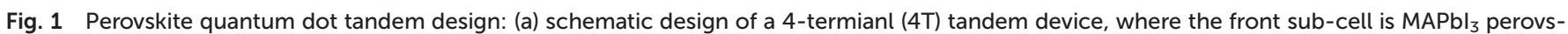

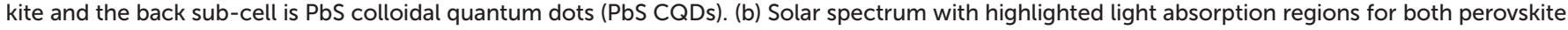
and CQD solar cells in this work. 
ness significantly reduces the device's transmittance. Therefore, we compared different thicknesses of the $\mathrm{Au}$ electrode on top of the perovskite cell, namely 10, 15 and $80 \mathrm{~nm}$. The highest transmittance in the IR region was observed for the $10 \mathrm{~nm}$ Au layer (Fig. 2a). We incorporated here a patterned design of the Au electrode on the perovskite sub-cell, as shown in Fig. 1a and Fig. $\mathrm{S} 2 \uparrow$ to improve the charge collection and therefore increase the short-circuit current $\left(J_{\mathrm{sc}}\right)$, the fill factor (FF) and subsequently the PCE of the perovskite cell, without losing the cell semi-transparency.

As mentioned above, the incorporation of metal oxide on top of the $\mathrm{Au}$ in the solar cell should lead to improved device transmittance. Here we tested 3 different thicknesses of $\mathrm{MoO}_{3}$, namely 20, 30 and $40 \mathrm{~nm}$, on a $10 \mathrm{~nm}$ thick semi-transparent gold electrode. The transparency improvement was recorded for the $40 \mathrm{~nm}$ molybdenum(vi) oxide layer, resulting in $\sim 40 \%$ transmittance in the near-infrared region (see Fig. S3†). However, the devices fabricated with this interlayer modification suffered from significant losses in the current-voltage performance (see Fig. $\mathrm{S} 4 \dagger$ ). This was most probably influenced by interactions of $\mathrm{MoO}_{3}$ with the Spiro-OMeTAD layer.

In the next step, CQD-perovskite $4 \mathrm{~T}$ tandem devices were fabricated by stacking the semi-transparent $\mathrm{MAPbI}_{3}$ perovskite solar cell with a $10 \mathrm{~nm}$ Au electrode on top of the PbS CQD solar cell. Measurements of the current-voltage $(J-V)$ characteristics and power conversion efficiency (PCE) were carried out following previously reported methods. ${ }^{27,28}$ The $J-V$ characteristics of the best semi-transparent perovskite cell and $\mathrm{PbS}$ CQD solar cells, are shown in Fig. 3a. A Surlyn interlayer was applied in the tandem devices with the perovskite front-cell and $\mathrm{PbS}$ CQD back-cell. When the perovskite cell was applied on top of the CQDSC, a decrease in the PCE of the CQDSC was observed, as expected from the reduced light intensity reaching the bottom CQDSC in the tandem configuration. The incident photon-to-current conversion efficiency (IPCE) in Fig. 3b shows that the perovskite solar cell converts light up to almost $800 \mathrm{~nm}$, and that the CQDSC converts light up to around $1100 \mathrm{~nm}$. Finally, the efficiency of the $4 \mathrm{~T}$ tandem structure by combining the semi-transparent $\mathrm{MAPbI}_{3}$ front-cell and the $\mathrm{PbS}$ CQD back-cell using a surlyn interlayer was $18.9 \%$ (see Table 1). Therefore, a clear performance enhancement in the tandem cells compared to each single sub-cell was achieved due to better light utilization and reduced carrier thermalization. The statistics of the solar cell parameters for several cells are shown in Fig. S5. $\dagger$

To analyze the effect of the surlyn interlayer, the photovoltaic average parameters for tandem devices before and after inclusion of the surlyn interlayer were compared and the results are shown in Fig. 4. The same devices were compared with and without surlyn, to see the actual improvement of the surlyn incorporation for each device.

On the average, $\sim 13 \%$ increase in the PCE and $\sim 8 \%$ increase in $J_{\mathrm{sc}}$ were observed for filtered PbS CQDs solar cell samples after adding surlyn into the interlayer design (Fig. 4a). This shows that the surlyn interlayer improves the light transmission to the CQD bottom-cell, by the reduction of reflections at the interfaces. The 'surlyn encapsulation' approach also improved the optical stability of semi-transparent $\mathrm{MAPbI}_{3}$ devices. The non-encapsulated devices showed approximately $10 \%$ higher transmittance in the visible region in comparison with the encapsulated samples, over a period of 7 days under the AM 1.5 illumination in air, as seen in Fig. 4b. This shows that the degradation of the $\mathrm{MAPbI}_{3}$ perovskite layer in the encapsulated samples is also reduced.

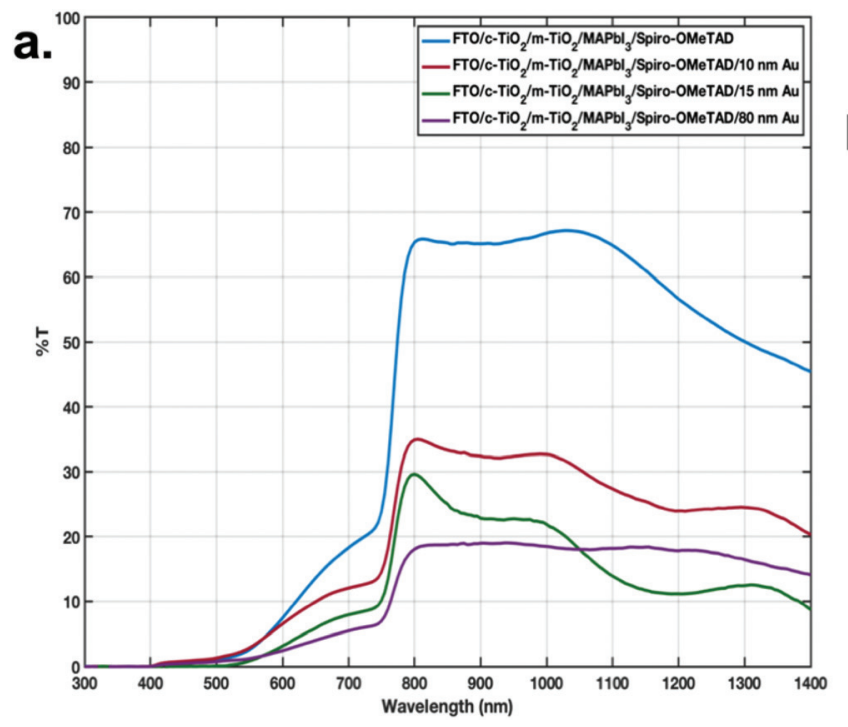

b.

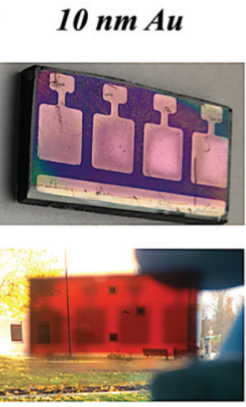

$15 \mathrm{~nm} \mathrm{Au}$

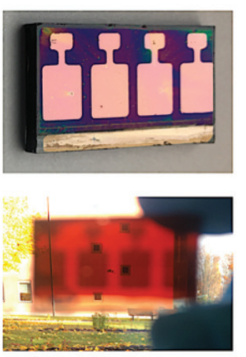

$80 \mathrm{~nm} \mathrm{Au}$

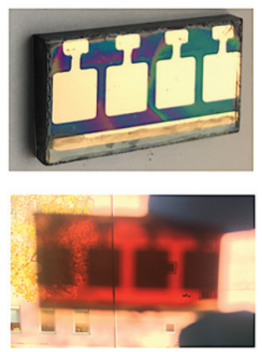

Fig. 2 Optimized IR transparency of the front-cell: (a) transmittance spectrum of the perovskite solar cell with the following structure: FTO glass/ compact $\mathrm{TiO}_{2} /$ mesoporous $\mathrm{TiO}_{2} / \mathrm{MAPbl}_{3}$ perovskite/Spiro-OMeTAD with different thicknesses of the Au electrode. (b) Pictures of the semi-transparent $\mathrm{MAPbl}_{3}$ solar cells of $2.4 \times 1.4 \mathrm{~cm}$ size with different thicknesses of the Au electrode: top and cross views. 

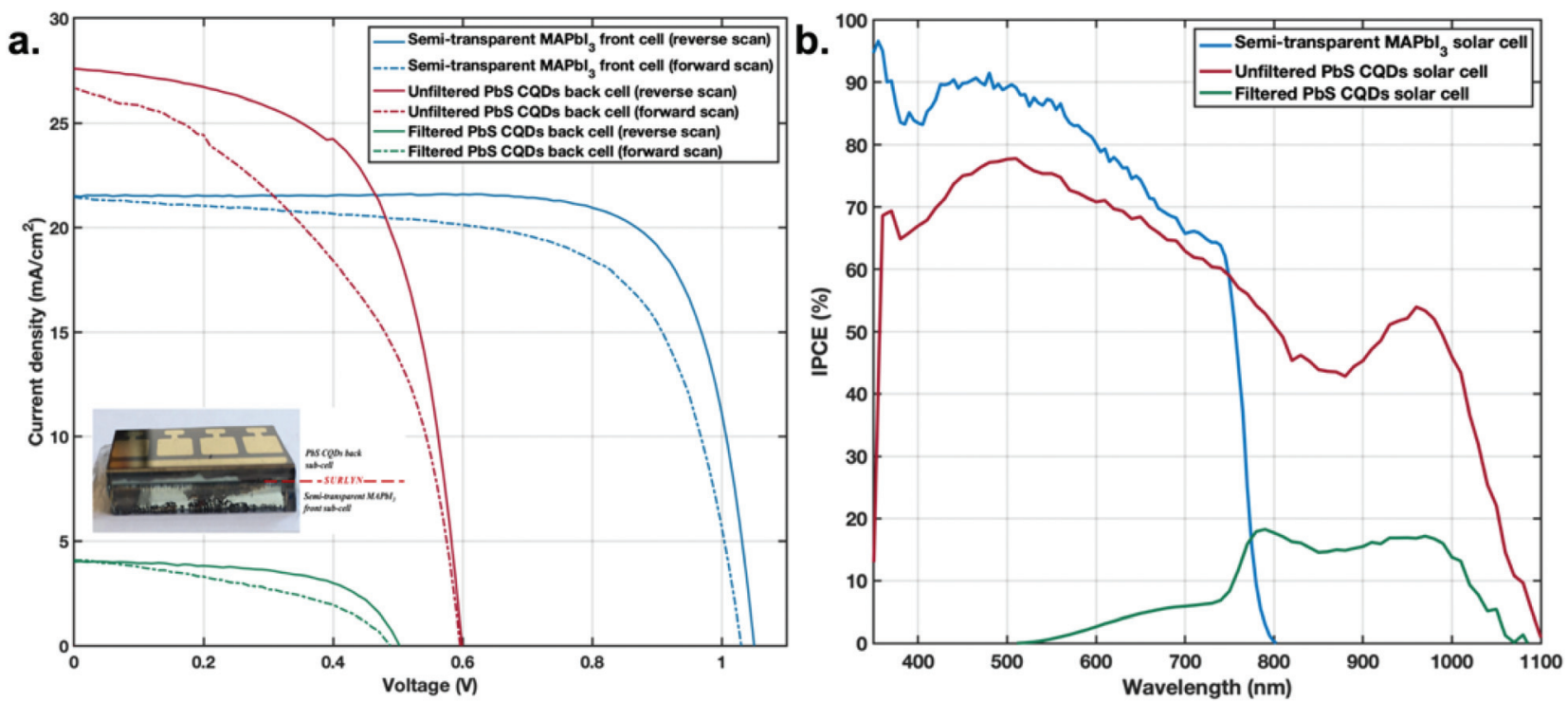

Fig. 3 Photovoltaic performance: (a) current-voltage ( $J-V$ characteristics of unfiltered (red line) and filtered (green line) PbS CQD devices and the semi-transparent $\mathrm{MAPb}_{3}$ device (blue line), under illumination $\left(1000 \mathrm{~W} \mathrm{~m}^{-2}, \mathrm{AM} 1.5 \mathrm{G}\right.$ ). The semi-transparent MAPbl 3 solar cell structure is as follows: FTO glass/compact $\mathrm{TiO}_{2} /$ mesoporous $\mathrm{TiO}_{2} / \mathrm{MAPbl}_{3}$ perovskite/Spiro-OMeTAD/10 nm Au/surlyn (25 $\left.\mu \mathrm{m}\right)$. The PbS CQD solar cell has the following configuration: indium doped tin oxide (ITO) glass/aluminum doped zinc oxide layer (AlZnO)/PbS-PbX ${ }_{2}$ (X-halogen molecule)/PbS-EDT (EDT-1,2-ethanedithiol) $/ 80 \mathrm{~nm} \mathrm{Au}$. PbS CQDs of $\lambda_{\max }=935 \mathrm{~nm}$ were used for these measurements. The filtered PbS CQD cell means that during the measurement, the semi-transparent $\mathrm{MAPb}_{3}$ solar cell was placed above the CQD cell - see the included profile picture of the perovskite-CQD tandem solar cell $(2.4 \times 1.4 \mathrm{~cm}$ in size). (b) IPCE spectra of the PbS CQD cell (red line), the MAPbl 3 perovskite cell with a $10 \mathrm{~nm}$ semi-transparent Au electrode (blue line) and the filtered PbS CQD cell with a semi-transparent $\mathrm{MAPbl}_{3}$ cell as the filter (green line).

Table 1 Summary of the photovoltaic performance of the champion 4T perovskite-CQD tandem solar cell, together with the performance of individual components

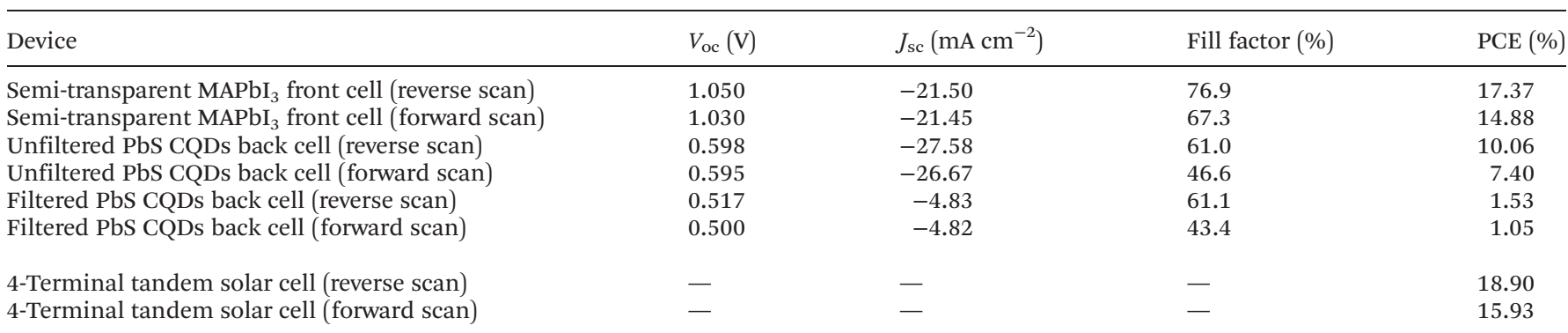

\section{Experimental}

\section{PbS CQD synthesis}

PbS CQDs were synthesized following a previously published method. ${ }^{29}$ First, $933 \mathrm{mg}$ of lead(II) oxide (PbO, 99.999\%, Sigma-Aldrich), $20 \mathrm{~g}$ of octadecane (ODE, technical grade, $90 \%$, Sigma-Aldrich) and $4.056 \mathrm{~g}$ of oleic acid (OA, technical grade, 90\%, Sigma-Aldrich) were mixed together. The solution was degassed under vacuum and then heated to $100{ }^{\circ} \mathrm{C}$ for $2 \mathrm{~h}$ under a nitrogen atmosphere. For the sulfur precursor, $356 \mathrm{mg}$ of hexamethyldisilathiane (HMDST, synthesis grade, SigmaAldrich) was dissolved in $10 \mathrm{~mL}$ of octadecane and degassed under vacuum, heated at $80{ }^{\circ} \mathrm{C}$ for $2 \mathrm{~h}$ and then loaded into a syringe. Next, the temperature of the PbO, ODE and OA solution was reduced to $90{ }^{\circ} \mathrm{C}$ and the HMDST solution was rapidly injected. Directly after the injection, the solution was removed from the heat and allowed to cool down to room temperature. Such synthesized CQDs were purified by precipitation with acetone, followed by centrifugation at $5000 \mathrm{rpm}$ for $5 \mathrm{~min}$ and redispersion in toluene (anhydrous, 99.8\%, SigmaAldrich). This washing was repeated twice and the final precipitate was dispersed in $10 \mathrm{~mL}$ of octane (reagent grade, $90 \%$, Sigma-Aldrich).

\section{AlZnO (AZO) sol-gel synthesis}

$2.195 \mathrm{~g}$ of zinc acetate dihydrate (99.5\%, Merck) and $198 \mathrm{mg}$ of aluminum(III) nitrate nonahydrate $(>98.5 \%$, Sigma-Aldrich) were mixed with $20 \mathrm{~mL}$ of ethanol. The solution was heated to $80{ }^{\circ} \mathrm{C}$ and stirred for $5 \mathrm{~min}$. Then $0.65 \mathrm{~mL}$ of ethanolamine (99.5\%, Sigma-Aldrich) was injected. Such a solution was left 

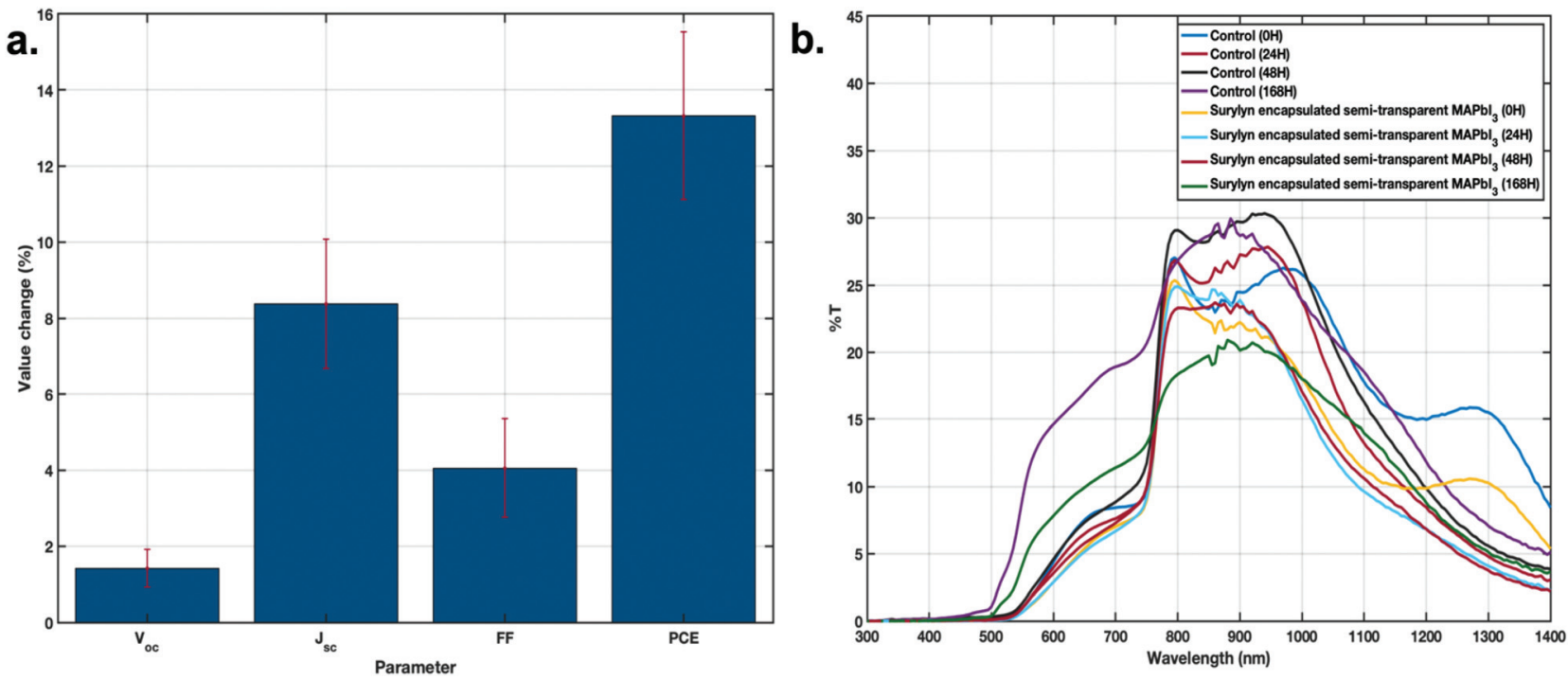

Fig. 4 (a) Percentage value of an average increase in photovoltaic parameters after incorporating surlyn into the tandem solar cell structure. For this statistical measurement, 12 samples of PbS CQD solar cells with $\lambda_{\max }$ values equal to both 901 and $935 \mathrm{~nm}$, respectively, were used. (b) Optical stability measurements for tandem solar cells after incorporation of surlyn into the device structure. The control sample is the non-encapsulated semi-transparent $\mathrm{MAPbl}_{3}$ solar cell with the following structure: $\mathrm{FTO} / \mathrm{c}-\mathrm{TiO}_{2} / \mathrm{m}-\mathrm{TiO}_{2} / \mathrm{MAPb}_{3}$ perovskite/Spiro-OMeTAD/10 nm Au. Surlyn-encapsulated $\mathrm{MAPbl}_{3}$ samples have the following composition: $\mathrm{FTO} / \mathrm{c}-\mathrm{TiO}_{2} / \mathrm{m}-\mathrm{TiO}_{2} / \mathrm{MAPbl}$. perovskite/Spiro-OMeTAD/10 nm Au/surlyn/ITO/AIZnO.

under stirring for $3 \mathrm{~h}$. After that, heating was stopped and the reaction mixture was allowed to cool down to room temperature.

\section{AZO film deposition}

Pre-etched indium-doped tin oxide (ITO) glass (ITO coated glass for R\&D use from Kaivo) was cleaned with detergent, acetone and ethanol. Then $20 \mathrm{~min}$ of UV-ozone treatment was performed. AZO sol-gel was filtered through a syringe filter $(0.45 \mu \mathrm{m})$ and $150 \mu \mathrm{m}$ of film was spin-coated on each pretreated glass sample of $2.4 \times 2.8 \mathrm{~cm}$ size at $3000 \mathrm{rpm}$ for $30 \mathrm{~s}$. Then, two-step annealing of the deposited film was performed under the following conditions: $200{ }^{\circ} \mathrm{C}$ for $30 \mathrm{~min}$, followed by $300{ }^{\circ} \mathrm{C}$ for $30 \mathrm{~min}$.

\section{CQD solar cells fabrication}

A solution ligand exchange process was performed according to a previously published paper. ${ }^{17} 7.5 \mathrm{~mL}$ of a $10 \mathrm{mg} \mathrm{mL}^{-1}$ solution of PbS CQDs in octane was vortexed for $5 \mathrm{~min}$ with $12 \mathrm{~mL}$ of $\mathrm{N}, \mathrm{N}$-dimethylformamide (anhydrous, 99.8\%, SigmaAldrich) solution containing $0.1 \mathrm{M}$ lead(II) iodide $\left(\mathrm{PbI}_{2}\right.$, 99.99\%, TCI), $0.04 \mathrm{M}$ lead(II) bromide $\left(\mathrm{PbBr}_{2},>98.0 \%\right.$, TCI) and $0.06 \mathrm{M}$ ammonium acetate (AA, for molecular biology, $\geq 98 \%$, Sigma-Aldrich). The reaction was subsequently washed with octane 3 times. Then, $12 \mathrm{~mL}$ of toluene was added. Precipitated particles were centrifuged at $4000 \mathrm{rpm}$ for $5 \mathrm{~min}$ and re-dispersed in butylamine, with a final concentration of $300 \mathrm{mg} \mathrm{mL}{ }^{-1} .45 \mu \mathrm{L}$ of such prepared INK was spin-coated on the AZO/ITO glass samples of $2.8 \times 2.4 \mathrm{~cm}$ size, using a twostep process: $1000 \mathrm{rpm}$ for $3 \mathrm{~s}$, followed by $1800 \mathrm{rpm}$ for $30 \mathrm{~s}$. The samples were annealed at $70{ }^{\circ} \mathrm{C}$ for $10 \mathrm{~min}$. PbS-EDT layers were deposited by spin coating in the following manner. First $50 \mu \mathrm{L}$ of a $50 \mathrm{mg} \mathrm{mL} \mathrm{mL}^{-1} \mathrm{PbS}$ CQD solution in octane was spin-coated at $1800 \mathrm{rpm}$ for $30 \mathrm{~s}$. Next, ligand exchange was performed by deposition of $200 \mu \mathrm{L}$ of $0.01 \%$ (V/V) 1,2-ethanedithiol (EDT, $\geq 98 \%$, Sigma-Aldrich) in acetonitrile (ACN, anhydrous, 99.8\%, Sigma-Aldrich) solution for 30 seconds and followed by spin-coating of this solution in $1800 \mathrm{rpm}$ for $30 \mathrm{~s}$. Finally, double acetonitrile rinsing was executed by two following spin-coatings of $200 \mu \mathrm{L}$ of ACN at $1800 \mathrm{rpm}$ for $30 \mathrm{~s}$ each. Then the samples were cut in half to obtain cells of $1.4 \times$ $2.4 \mathrm{~cm}$ size. As a final step, $80 \mathrm{~nm}$ of gold contact was evaporated, using a thermal-deposition method.

\section{MAPbI $_{3}$ solar cell fabrication}

Perovskite solar cells were fabricated using TEC15 fluorinedoped tin oxide (FTO) glass from Pilkington. FTO glass was chemically etched using $\mathrm{Zn}$ powder and a $2 \mathrm{M}$ hydrochloric acid solution. Multiple glass cleaning steps were carried out: RBS/water solution, acetone, ethanol and UV-Ozone treatment. Next, the electron transport layer was deposited. First, a compact titanium dioxide layer $\left(\mathrm{c}-\mathrm{TiO}_{2}\right)$ was prepared by hightemperature spray pyrolysis of a titanium diisopropoxide bis (acetylacetonate) (75 wt\% in isopropanol, Sigma-Aldrich) solution in ethanol (1:9 volume ratio). This layer was deposited at $500{ }^{\circ} \mathrm{C}$ and annealed for $30 \mathrm{~min}$ at the same temperature. After cooling down the samples to room temperature, they were cut into rectangles of $1.4 \times 2.4 \mathrm{~cm}$ size and a mesoporous $\mathrm{TiO}_{2}$ layer $\left(\mathrm{m}-\mathrm{TiO}_{2}\right)$ was deposited as follows: $1.5 \mathrm{~g}$ of $\mathrm{TiO}_{2}$ paste (30 NR-D, GreatCell Solar) was dispersed in $10 \mathrm{~mL}$ of ethanol and spin-coated on the $\mathrm{c}-\mathrm{TiO}_{2}$ layer at $4000 \mathrm{rpm}$ for 20 s. Then, such prepared samples were annealed at $450{ }^{\circ} \mathrm{C}$ for 
$30 \mathrm{~min}$. The $\mathrm{MAPbI}_{3}$ perovskite absorber layer was deposited inside a $\mathrm{N}_{2}$ glovebox. The precursor of the perovskite films was prepared by dissolving $415 \mathrm{mg}$ of $\mathrm{PbI}_{2}$ and $143 \mathrm{mg}$ of methylammonium iodide (MAI, 99.99\%, Dyenamo) in DMF : DMSO (4:1 volume ratio) solvent mixture. The perovskite layer was spin-coated onto the $\mathrm{m}-\mathrm{TiO}_{2}$ at $4000 \mathrm{rpm}$ for $30 \mathrm{~s}$. After $15 \mathrm{~s}$ of spin-coating, chlorobenzene (CB, anhydrous, 99.8\%, SigmaAldrich) was added dropwise onto the substrate. Such fabricated substrates were annealed at $90{ }^{\circ} \mathrm{C}$ for $30 \mathrm{~min}$. The hole transporting layer (HTL), in the form of spiro-OMeTAD (min. 99.8\%, Borun New Material technology Ltd), was deposited right after the fabrication of perovskite films. The spiroOMeTAD solution was prepared beforehand by dissolving $52 \mathrm{mg}$ of spiro-OMeTAD in $568.8 \mu \mathrm{L}$ of chlorobenzene. Next, $20.5 \mu \mathrm{L}$ of 4 -tertbutyl-pyridine was added, followed by $11.8 \mu \mathrm{L}$ of a lithium bis(trifluoromethanesulfonyl)imide solution in acetonitrile $\left(516 \mathrm{mg} \mathrm{mL}^{-1}\right)$ and $5.09 \mu \mathrm{L}$ of a tris(2-(1H-pyrazol1-yl)-4-tert-butylpyridine)cobalt(III) tri[bis(trifluoromethane)sulfonimide] (FK 209 Co(III)-TFSI salt) solution in acetonitrile (37.5 $\mathrm{mg} \mathrm{mL}^{-1}$ ). This solution was spin-coated on top of the perovskite films at $2500 \mathrm{rpm}$ for $30 \mathrm{~s}$. After that, the samples were kept in the dark and under an ambient atmosphere for oxidation.

\section{Interlayer modifications}

All prepared devices were of $1.4 \times 2.4 \mathrm{~cm}$ size. For the opaque devices, $80 \mathrm{~nm}$ of gold was evaporated on top of spiroOMeTAD by thermal-deposition in a vacuum. For the semitransparent devices, three different modifications were applied. The first type of device was fabricated with a thin $\mathrm{Au}$ back electrode, prepared by the deposition of a $10 \mathrm{~nm} \mathrm{Au}$ layer, followed by an additional $70 \mathrm{~nm} \mathrm{Au}$ frame on the edges of the $10 \mathrm{~nm}$ Au contact (see Fig. 1a) for better charge collection. For the second type of semi-transparent device, the aforementioned thin Au back electrode was topped with a molybdenum(vi) oxide $\left(\mathrm{MoO}_{3}, 99.97 \%\right.$, Sigma-Aldrich) layer for better transmittance. The third type of semi-transparent device was fabricated by deposition of the aforementioned thin $\mathrm{Au}$ back electrode topped with a $25 \mu \mathrm{m}$ surlyn piece to minimize reflections. Gold and $\mathrm{MoO}_{3}$ were deposited using thermal evaporation. Surlyn was deposited by placing the perovskite cell on the hotplate, placing a piece of surlyn on top of the cell and heating the hotplate to $70{ }^{\circ} \mathrm{C}$. Then, the CQD SC (glass side) was placed on top of the surlyn and both cells were manually pressed together.

\section{Solar cell performance measurements and characterization}

IPCE spectra were recorded with a computer-controlled system comprised of a xenon lamp (Spectra products ASBXE 175), a monochromator (Spectra Products CM110), a LabJack U6 and a potentiostat (PINE AFRDE 5). Measurements were executed after a previously performed calibration with a certified reference solar cell (Fraunhofer ISE). Transmission measurements were performed with a PerkinElmer Lambda 900 spectrometer. Photovoltaic performance was measured by illuminating the samples with AM1.5G sunlight provided by a self-calibrating
WaveLabs SINUS-70 solar simulator with UV and IR range extenders while measuring the cell's current-voltage response with an Ossila X200 source meter. Black masking was applied on top of the cell with an aperture of $0.065 \mathrm{~cm}^{2}$ for filtered and unfiltered PbS CQD back sub-cells and of $0.125 \mathrm{~cm}^{2}$ for semi-transparent $\mathrm{MAPbI}_{3}$ solar cells.

\section{Conclusions}

In conclusion, tandem solar cells based on a methylammonium lead iodide $\left(\mathrm{MAPbI}_{3}\right)$ perovskite solar cell (PSC) as the front-cell and a lead sulfide (PbS) colloidal quantum dot (CQD) solar cell as the back-cell, with different interlayer modifications, have been investigated. The $\mathrm{MAPbI}_{3}$ perovskite top cell, with a thin semi-transparent $10 \mathrm{~nm}$ gold electrode, yielded a PCE of $\sim 17.3 \%$ and increased transmittance of IR light in comparison with the standard $80 \mathrm{~nm}$ Au electrode. Further development with an additional $\mathrm{MoO}_{3}$ layer was also performed, leading to enhanced transmittance of IR light, but with lower photovoltaic performance compared to the case without the $\mathrm{MoO}_{3}$ layer. Therefore, incorporation of surlyn encapsulation on top of the thin $\mathrm{Au}$ electrode was instead investigated, showing the enhanced optical transmittance of infrared light to the PbS CQD back cell. The surlyn interlayer also leads to the increased optical stability of the perovskite solar cell. The $J-V$ performance of the four-terminal tandem solar cell with $\mathrm{MAPbI}_{3}$ perovskite as the front cell and $\mathrm{PbS}$ CQDs as the back sub-cell and a surlyn interlayer was demonstrated, with an efficiency of $18.9 \%$. The surlyn interlayer resulted in around 13\% enhanced PCE compared to a tandem cell without the surlyn interlayer. These results show that modifications of the interlayer in perovskite-CQD $4 \mathrm{~T}$ tandem devices can lead to better utilization of the infrared part of the light spectrum and higher stability. Furthermore, incorporation of different perovskite structures or adjustment in the size of the quantum dots in the CQD solar cell could also significantly improve the tandem performance. Consequently, such tandem devices with an optimized interlayer may be a very interesting and promising alternative for next-generation photovoltaics.

\section{Conflicts of interest}

There are no conflicts to declare.

\section{Acknowledgements}

The authors acknowledge the financial support obtained from the Swedish Energy Agency, Olle Engkvist Foundation and ÅForsk. This work was also supported by the National Science Foundation of China (51872014), the Recruitment Program of Global Experts, the Fundamental Research Funds for the Central Universities (YWF-20-BJ-J-637) and the "111" project (B17002). 


\section{References}

1 A. Polman, M. Knight, E. C. Garnett, B. Ehrler and W. C. Sinke, Science, 2016, 352, aad4424.

2 Q. Wali, N. K. Elumalai, Y. Iqbal, A. Uddin and R. Jose, Renewable Sustainable Energy Rev., 2018, 84, 89-110.

3 M. A. Green, Y. Hishikawa, W. Warta, E. D. Dunlop, D. H. Levi, J. Hohl-Ebinger and A. W. H. Ho-Baillie, Prog. Photovoltaics Res. Appl., 2017, 25, 668-676.

4 R. Cariou, J. Benick, P. Beutel, N. Razek, C. Flotgen, M. Hermle, D. Lackner, S. W. Glunz, A. W. Bett, M. Wimplinger and F. Dimroth, IEEE J. Photovoltaics, 2017, 7, 367-373.

5 A. Kojima, K. Teshima, Y. Shirai and T. Miyasaka, J. Am. Chem. Soc., 2009, 131, 6050-6051.

6 https://www.nrel.gov/pv/assets/pdfs/best-research-cellefficiencies.20190802.pdf.

7 S. De Wolf, J. Holovsky, S. J. Moon, P. Löper, B. Niesen, M. Ledinsky, F. J. Haug, J. H. Yum and C. Ballif, J. Phys. Chem. Lett., 2014, 5, 1035-1039.

8 K. Galkowski, A. Mitioglu, A. Miyata, P. Plochocka, O. Portugall, G. E. Eperon, J. T. W. Wang, T. Stergiopoulos, S. D. Stranks, H. J. Snaith and R. J. Nicholas, Energy Environ. Sci., 2016, 9, 962-970.

9 D. P. McMeekin, G. Sadoughi, W. Rehman, G. E. Eperon, M. Saliba, M. T. Hörantner, A. Haghighirad, N. Sakai, L. Korte, B. Rech, M. B. Johnston, L. M. Herz and H. J. Snaith, Science, 2016, 351, 151-155.

10 L. M. Herz, ACS Energy Lett., 2017, 2, 1539-1548.

11 G. E. Eperon, M. T. Hörantner and H. J. Snaith, Nat. Rev. Chem., 2017, 0095.

12 G. E. Eperon, T. Leijtens, K. A. Bush, R. Prasanna, T. Green, J. T. W. Wang, D. P. McMeekin, G. Volonakis, R. L. Milot and R. May, Science, 2016, 861-865.

13 M. H. Futscher and B. Ehrler, ACS Energy Lett., 2017, 20892095.

14 L. Hu, Z. Zhang, R. J. Patterson, Y. Hu, W. Chen, C. Chen, D. Li, C. Hu, C. Ge, Z. Chen, L. Yuan, C. Yan, N. Song, Z. L. Teh, G. J. Conibeer, J. Tang and S. Huang, Nano Energy, 2018, 46, 212-219.

15 X. Zhang, D. Jia, C. Hägglund, V. A. Öberg, J. Du, J. Liu and E. M. J. Johansson, Nano Energy, 2018, 53, 373-382.
16 M. J. Choi, F. P. García de Arquer, A. H. Proppe, A. Seifitokaldani, J. Choi, J. Kim, S. W. Baek, M. Liu, B. Sun, M. Biondi, B. Scheffel, G. Walters, D. H. Nam, J. W. Jo, O. Ouellette, O. Voznyy, S. Hoogland, S. O. Kelley, Y. S. Jung and E. H. Sargent, Nat. Commun., 2020, 11, 1-9.

17 M. Liu, O. Voznyy, R. Sabatini, F. Pelayo García De Arquer, R. Munir, A. Hesham Balawi, X. Lan, F. Fan, G. Walters, A. R. Kirmani, S. Hoogland, F. Laquai, A. Amassian and E. H. Sargent, Nat. Mater., 2017, 16, 258-263.

18 E. H. Sargent, Nat. Photonics, 2012, 6, 133-135.

19 A. H. Ip, A. Kiani, I. J. Kramer, O. Voznyy, H. F. Movahed, L. Levina, M. M. Adachi, S. Hoogland and E. H. Sargent, ACS Nano, 2015, 9, 8833-8842.

20 A. Karani, L. Yang, S. Bai, M. H. Futscher, H. J. Snaith, B. Ehrler, N. C. Greenham and D. Di, DOI: 10.1021/ acsenergylett.8b00207.

21 Y. Zhang, M. Gu, N. Li, Y. Xu, X. Ling, Y. Wang, S. Zhou, F. Li, F. Yang, K. Ji, J. Yuan and W. Ma, J. Mater. Chem. A, 2018, 6, 24693-24701.

22 A. Manekkathodi, B. Chen, J. Kim, S. W. Baek, B. Scheffel, Y. Hou, O. Ouellette, M. I. Saidaminov, O. Voznyy, V. E. Madhavan, A. Belaidi, S. Ashhab and E. Sargent, J. Mater. Chem. A, 2019, 7, 26020-26028.

23 T. Leijtens, K. A. Bush, R. Prasanna and M. D. McGehee, Nat. Energy, 2018, 3, 828-838.

24 C. Li, Y. Wang and W. C. H. Choy, Small Methods, 2020, 4, $1-19$.

25 X. Zhang, C. Hägglund, M. B. Johansson, K. Sveinbjörnsson and E. M. J. Johansson, Adv. Funct. Mater., 2016, 26, 19211929.

26 X. Zhang, C. Hä and E. M. J. Johansson, Energy Environ. Sci., 2017, 10, 216.

27 D. Zhao, Y. Yu, C. Wang, W. Liao, N. Shrestha, C. R. Grice, A. J. Cimaroli, L. Guan, R. J. Ellingson, K. Zhu, X. Zhao, R. G. Xiong and Y. Yan, Nat. Energy, 2017, 2, 1-7.

28 J. Tong, Z. Song, D. H. Kim, X. Chen, C. Chen, A. F. Palmstrom, P. F. Ndione, M. O. Reese, S. P. Dunfield, O. G. Reid, J. Liu, F. Zhang, S. P. Harvey, Z. Li, S. T. Christensen, G. Teeter, D. Zhao, M. M. Al-Jassim, M. F. A. M. Van Hest, M. C. Beard, S. E. Shaheen, J. J. Berry, Y. Yan and K. Zhu, Science, 2019, 364, 475-479.

29 G. H. Kim, B. Walker, H. B. Kim, E. H. Sargent, J. Park and J. Y. Kim, Adv. Mater., 2014, 26, 3321-3327. 